\title{
A virus-based single-enzyme nanoreactor
}

\author{
MARTA COMELLAS-ARAGONĖ' ${ }^{1}$, HANS ENGELKAMP ${ }^{1 *}$, VICTOR I. CLAESSEN ${ }^{1}$, \\ NICO A. J. M. SOMMERDIJK², ALAN E. ROWAN ${ }^{1}$, PETER C. M. CHRISTIANEN ${ }^{1}$, JAN C. MAAN ${ }^{1}$, \\ BENEDICTUS J. M. VERDUIN${ }^{3}$, JEROEN J. L. M. CORNELISSEN ${ }^{1 *}$ AND ROELAND J. M. NOLTE \\ 'Institute for Molecules and Materials, Radboud University Nijmegen, Toernooiveld 1, 6525 ED Nijmegen, The Netherlands \\ ${ }^{2}$ Laboratory of Macromolecular and Organic Chemistry and Soft Matter CryoTEM Research Unit, Department of Biomedical Engineering, Eindhoven \\ University of Technology, PO Box 513, 5600 MB, Eindhoven, The Netherlands \\ ${ }^{3}$ Laboratory of Virology, Wageningen University, Binnenhaven 11, 6709 PD Wageningen, The Netherlands \\ *e-mail: h.engelkamp@science.ru.nl; j.cornelissen@science.ru.nl
}

Most enzyme studies are carried out in bulk aqueous solution, at the so-called ensemble level, but more recently studies have appeared in which enzyme activity is measured at the level of a single molecule, revealing previously unseen properties ${ }^{1-4}$. To this end, enzymes have been chemically or physically anchored to a surface, which is often disadvantageous because it may lead to denaturation. In a natural environment, enzymes are present in a confined reaction space, which inspired us to develop a generic method to carry out single-enzyme experiments in the restricted spatial environment of a virus capsid. We report here the incorporation of individual horseradish peroxidase enzymes in the inner cavity of a virus, and describe single-molecule studies on their enzymatic behaviour. These show that the virus capsid is permeable for substrate and product and that this permeability can be altered by changing $\mathrm{pH}$.

In recent reports, protein capsids and viruses have been studied as containers, as potential reaction vessels ${ }^{5-8}$, as well-defined hosts $^{9-12}$, as nanotemplates ${ }^{13-18}$ and as synthetic platforms ${ }^{19-21}$. To the best of our knowledge, no enzyme-loaded nanocontainer has been assembled, let alone studied, at the single-enzyme level.

The container described here, the cowpea chlorotic mottle virus (CCMV), has an outer diameter $D$ of $28 \mathrm{~nm}$ and a well-defined inner cavity with a diameter of $18 \mathrm{~nm}$. The virus is composed of 180 identical coat protein subunits, which encapsulate the viral RNA (ref. 22). An interesting feature of the CCMV virus is its $\mathrm{pH}$-dependent gating behaviour ${ }^{23}$. CCMV virions can, depending on $\mathrm{pH}$, disassemble in vitro into protein dimers and RNA. After removal of RNA and with a change in $\mathrm{pH}$, the purified viral coat protein subunits will easily self-organize and reform the capsids $^{24,25}$. The reversible $\mathrm{pH}$-dependent assembly/disassembly of the CCMV capsid provides a unique molecular gating mechanism for controlling the containment and release of entrapped material. We have used this behaviour of the CCMV capsid to encapsulate the enzyme horseradish peroxidase (HRP) as a model system to investigate single-enzyme processes in this virus nanoreactor. The use of the CCMV capsid as a container was first optimized with the proteins myoglobin and Dronpa ${ }^{26,27}$ in order to control the encapsulation and characterization process (see Supplementary Information, page 3).

The purification of the CCMV virus and the removal of its RNA were carried out according to the literature ${ }^{24,25}$ (see Supplementary
Information, page 2). The monodispersity of the virus was confirmed by fast protein liquid chromatography (FPLC; $V_{\text {virus }}=1.12 \mathrm{ml}$, see Supplementary Information, Fig. S1a) transmission electron microscopy (TEM; Fig. 1a). According to the analyses, the viral coat protein at $\mathrm{pH} 5$ forms particles having the same spherical shape and size as the virus $(D=28 \mathrm{~nm})$, but with a larger cavity due to the absence of RNA (Fig. 1a (inset); see also Supplementary Information, Fig. S1b).

After the optimal encapsulation conditions were determined, the loading of HRP was carried out by the abovementioned $\mathrm{pH}$-dependent disassembly/reassembly process (Fig. 2a), which was monitored by TEM and FPLC. Initially, the capsid was transformed into protein dimers, indicated by a peak at $V=1.78 \mathrm{ml}$ in the FPLC (Fig. 1b). After addition of excess HRP, the capsid was reassembled while incorporating the guest enzyme (see Methods). As the objective was to perform singleenzyme studies, the concentration of enzyme was selected to be such that there was only one or no enzyme present per capsid. By determining the number of capsids per unit area by atomic force microscopy (AFM) and comparing it with the number of fluorescent (active) particles as found by fluorescence confocal microscopy (see below, Fig. 3c) in the same area, we confirmed that only one HRP was present per capsid or none at all.

Co-elution of the guest protein and capsid was observed in all encapsulation experiments (that is, with myoglobin, Dronpa and HRP). Detailed FPLC, TEM and fluorescence spectroscopy analyses of HRP encapsulation are shown in Fig. 2b-e. Similar data were obtained for the two model proteins (see Supplementary Information, Figs S2 and S3). FPLC traces for the HRP-containing CCMV capsid point to the successful reassembly of the viral cage after the encapsulation process (Fig. 2c), showing the same elution volume $(V=1.12 \mathrm{ml})$ as the original capsid (Fig. 2b). The signal at $V=1.8 \mathrm{ml}$ in Fig. 2c corresponds to the elution volume of free HRP (Fig. 2d; the high absorbance at $403 \mathrm{~nm}$ is due to the heme group present in the protein). The material eluting at $V=0.9 \mathrm{ml}$ in Fig. $2 \mathrm{~b}$ and $\mathrm{c}$ corresponds to the elution volume of larger aggregates formed by the viral coat protein, which is not uncommon for CCMV capsids. The correct reassembly of the capsids with and without HRP was further proven by cryo-TEM analysis (Fig. 2b,c (insets); see also Supplementary Information, Fig. S4). In both cases, identical particles were observed. Under the 

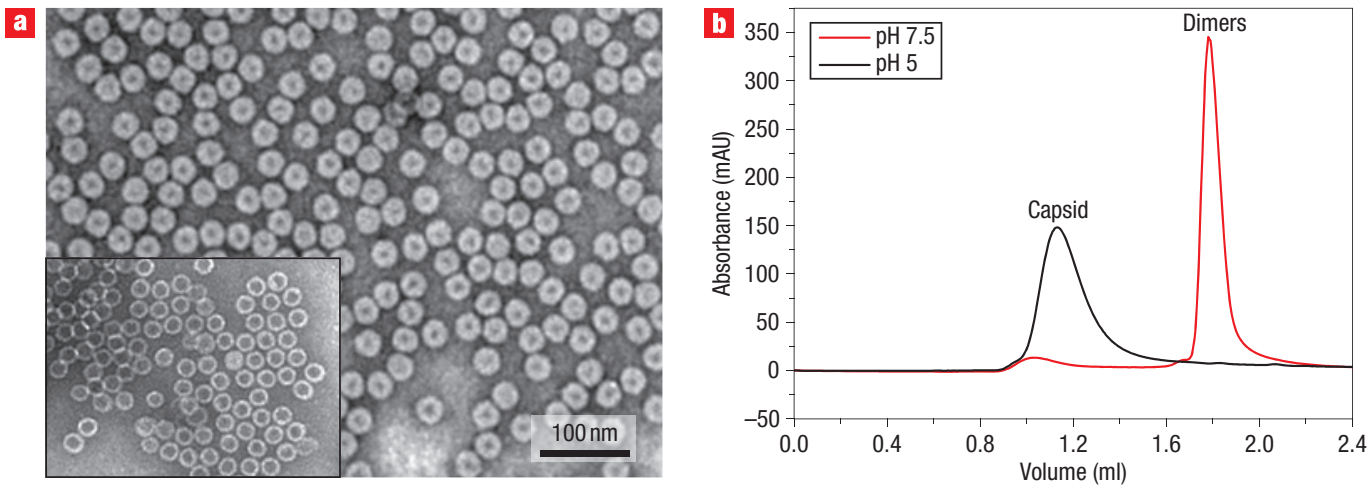

Figure 1 Characterization of CCMV and the empty CCMV capsid. a, TEM (negative staining) of the CCMV virus and the empty capsid (inset). $\mathbf{b}$, Size-exclusion FPLC of the CCMV protein at pH 5 (black curve) and at pH 7.5 (red curve), illustrating the difference in assembly behaviour depending on the acidity of the solution in which it is dissolved. The protein forms capsids at $\mathrm{pH} 5$, which fall apart into protein dimers when the $\mathrm{pH}$ is raised to 7.5.
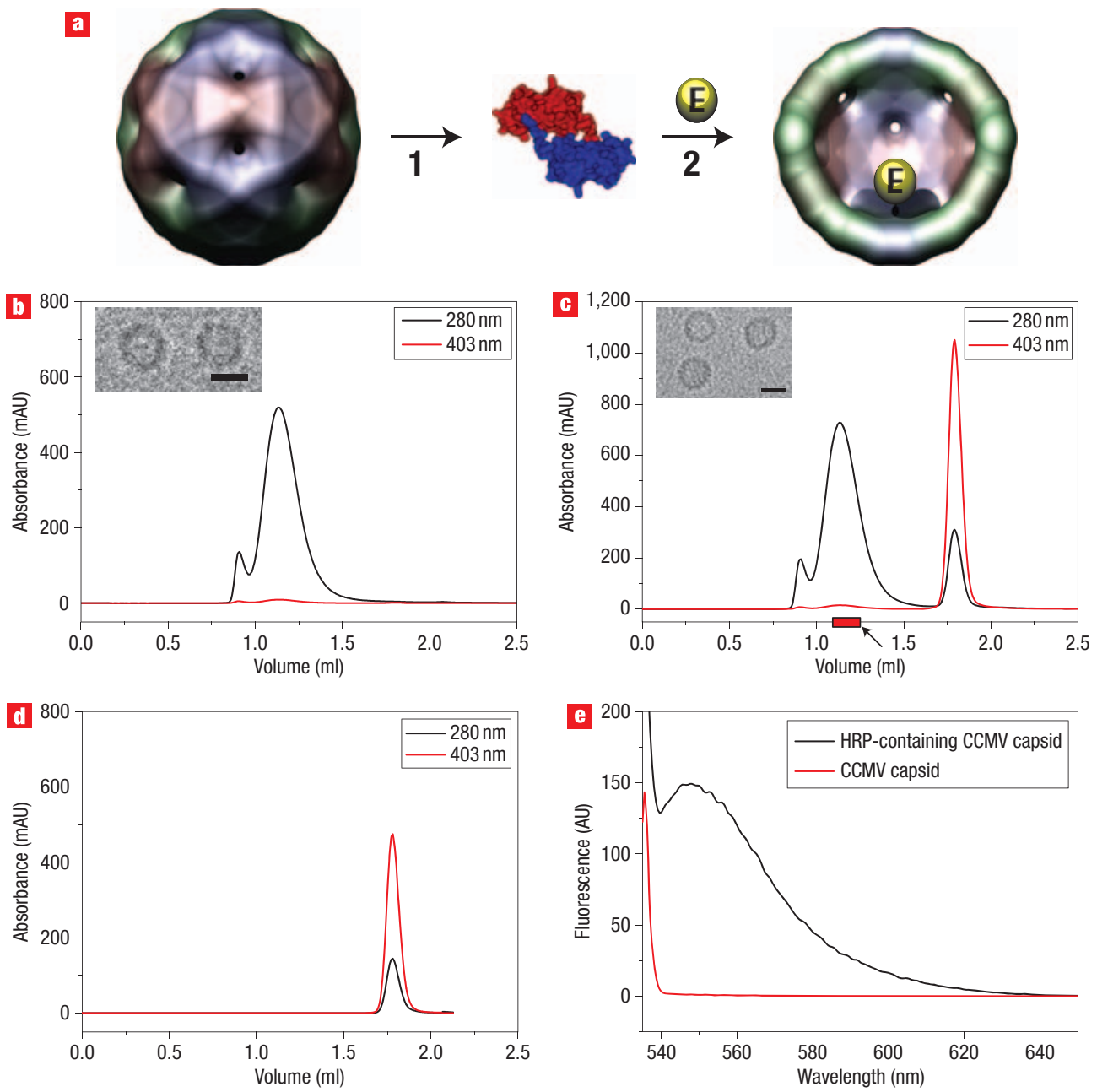

Figure 2 Inclusion of HRP in the virus capsid. a, Schematic pathway for inclusion of a protein or an enzyme in the CCMV capsid. After disassembling the CCMV capsid into dimers (step 1, pH 7.5), the guest protein (E) is added and the CCMV capsid assembled again by decreasing the pH (step 2, pH 5). b, Size-exclusion FPLC of the CCMV capsid with the absorbance of eluted materials monitored at two different wavelengths. The small shoulder to the left of the main peak corresponds to protein aggregates larger than the usual capsid. Inset: cryo-TEM image of the CCMV capsid (scale bar $=20 \mathrm{~nm}$ ). c, Size-exclusion FPLC of the HRP-containing CCMV capsid. The peak at an elution volume of $1.8 \mathrm{ml}$ corresponds to free HRP (see panel $\mathbf{d}$ ). The arrow points to a fraction that was collected for further analysis (see panel e). Inset: cryo-TEM image of the HRP-containing CCMV capsid (bar $=20 \mathrm{~nm})$. d. Size-exclusion FPLC of HRP. e, Emission spectra $\left(\lambda_{\text {exc }}=530 \mathrm{~nm}\right)$ of the HRP-containing CCMV capsid fraction collected from FPLC experiments (as indicated in panel c) and the corresponding fraction of the CCMV capsid devoid of HRP obtained in an analogous fashion. 
conditions used, individual proteins, such as coat protein and HRP, are not visualized because of their small size and low contrast. Additional evidence for co-elution of the capsid and HRP $(V=1.12 \mathrm{ml})$ comes from analysis of the concentrated fractions from FPLC (see the arrow in Fig. 2c) by fluorescence spectroscopy (Fig. 2e; see Methods). Test experiments using a colorimetric assay (2,2'-azino-bis-(3-ethylbenzthiazoline-6-sulphonic acid) (ABTS) and $\mathrm{H}_{2} \mathrm{O}_{2}$ ) revealed that the HRP-containing CCMV capsid still possessed substantial enzymatic activity (see Supplementary Information, Fig. S5).

The enzymatic activity of the HRP molecules inside the CCMV capsid was examined at the single-molecule level with a confocal fluorescence microscope using the fluorogenic substrate dihydrorhodamine 6G (Figs 3 and 4; see Methods) ${ }^{28}$. HRP catalyses the oxidation of this non-fluorescent substrate to produce rhodamine $6 \mathrm{G}$, which is a highly fluorescent dye that can be easily monitored. Two solutions were prepared: one containing HRP encapsulated inside some of the CCMV capsids and a control solution containing a mixture of empty CCMV capsid and free HRP (Fig. 3a, b). Typical images of the activity of HRP inside the CCMV capsid after $10 \mathrm{~min}$ of incubation of the mixture are shown in Fig. 3c. Bright diffraction-limited spots are clearly visible, which are attributed to diffusion of the substrate through the capsid pores, conversion, and diffusion of the product out of the capsid. Also, in the case of the mixture of non-encapsulated HRP and empty CCMV capsid, during catalysis, localized fluorescence is observed, but with a much reduced intensity (see Supplementary Information, Fig. S6). In both experiments the localized fluorescence is a result of the continuous formation of the enzyme-product complex ${ }^{4}$, but when the enzyme is encased inside a virus capsid the disappearance of the fluorescence is delayed because of product accumulation. Interestingly, in a blank experiment in which HRP was deposited in the absence of the CCMV capsid, no fluorescence was observed, probably as a result of denaturation of the enzyme on the glass (not shown).

In order to further prove that the bright fluorescent spots in Fig. $3 c$ are the result of enzymatic activity localized inside the capsid, the fluorescence of one of these bright spots was followed with time (Fig. 4a). A strongly fluctuating intensity trace was clearly visible over time, whereas a time trace at a dark area away from the capsid showed only poissonian noise. In the case of the non-encapsulated enzyme in the presence of empty capsid, time traces measured at the fluorescent spots (Fig. 4b) also showed a strongly fluctuating behaviour. The latter traces were characterized by alternating bursts of fluorescence, followed by relatively long periods of background noise. To analyse the above observations, autocorrelation curves $G(t)$ were calculated from the time traces in Fig. 4a,b, according to

$$
G(t)=\frac{\sum_{i}\left(I_{i}-\bar{I}\right)\left(I_{i+t}-\bar{I}\right)}{\sum_{i}\left(I_{i}-\bar{I}\right)^{2}} .
$$

The curves are plotted in Fig. 4c, and interestingly, the two curves show completely different signatures. The curve for the HRPincluded CCMV complex (red squares in Fig. 4c) fits well with a simple diffusion model

$$
G(t)=\frac{1}{\bar{N}} \frac{1}{1+\left(t / \tau_{\mathrm{D}}\right)},
$$

where $\bar{N}$ is the average number of fluorescent product molecules in the observed volume, and $\tau_{\mathrm{D}}$ is the characteristic diffusion time ${ }^{29}$. In the present example, the best fit is obtained for $\tau_{D}=19.5 \mathrm{~ms}$.
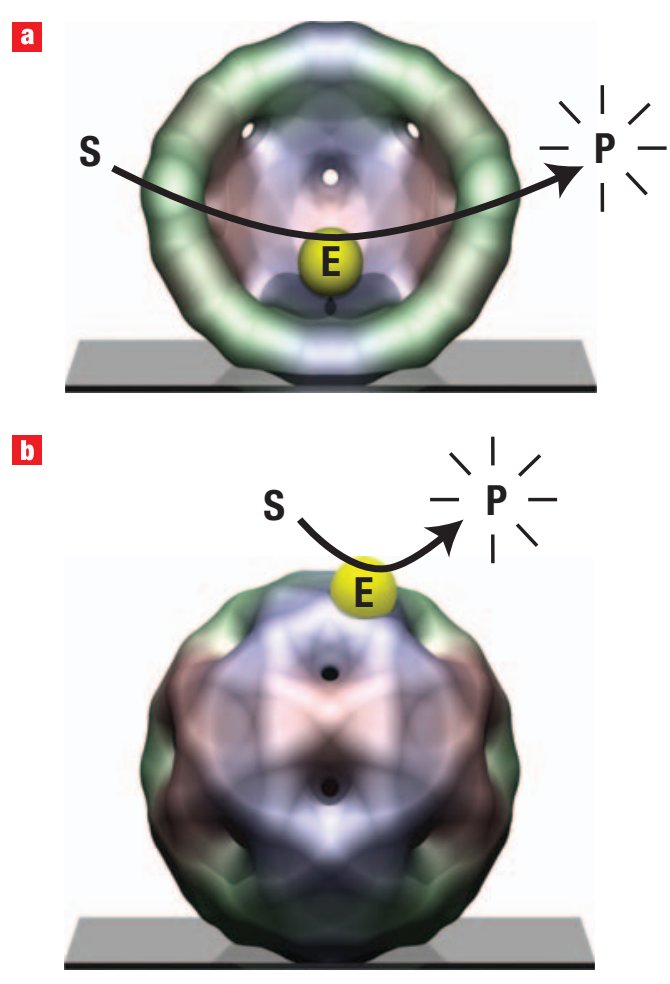

\&

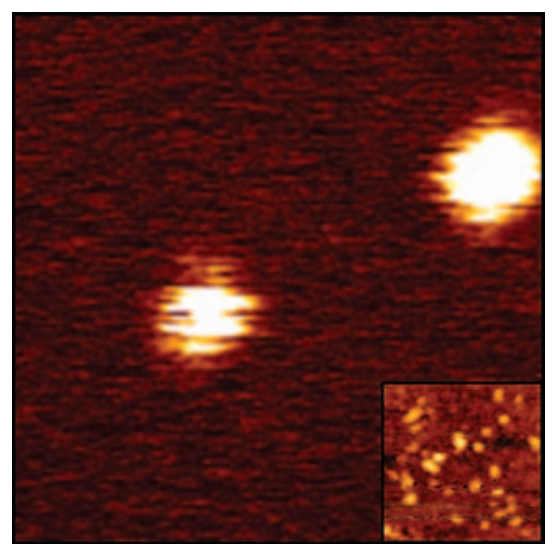

Figure 3 Enzyme activity in the presence of single capsids. a, When HRP is encapsulated inside a capsid, substrate molecules (S) diffuse into the capsid and are subsequently converted to product molecules $(\mathrm{P})$, which then accumulate before diffusing out through the capsid pores. $\mathbf{b}$, If HRP is adsorbed on the outside of a capsid, diffusion of substrate (S) or product (P) molecules in or out of the capsid has no bearing on the activity of the enzyme. c, A typical confocal fluorescence image $(1.68 \mu \mathrm{m} \times 1.68 \mu \mathrm{m})$ showing the formation of a fluorescent product (rhodamine $6 \mathrm{G}$ ) from a non-fluorescent substrate (dihydrorhodamine $6 \mathrm{G}$ ) by HRP encapsulated inside a capsid. Inset: AFM image (to scale) at the same sample location, showing that only a small fraction of the capsids contain an active enzyme molecule. One in every 130 capsids is estimated to contain HRP.

For rhodamine in pure water, a $\tau_{\mathrm{D}}$ value of $0.04 \mathrm{~ms}$ is reported ${ }^{30}$, a difference of almost three orders of magnitude compared with the HRP-containing CCMV capsid. We attribute this difference in $\tau_{\mathrm{D}}$ to the hampered diffusion of the product molecules through the pores in the CCMV capsid wall. The pore size of the intact virus is known to depend on the $\mathrm{pH}$ (ref. 22). At $\mathrm{pH} \mathrm{5,} \mathrm{the}$ 

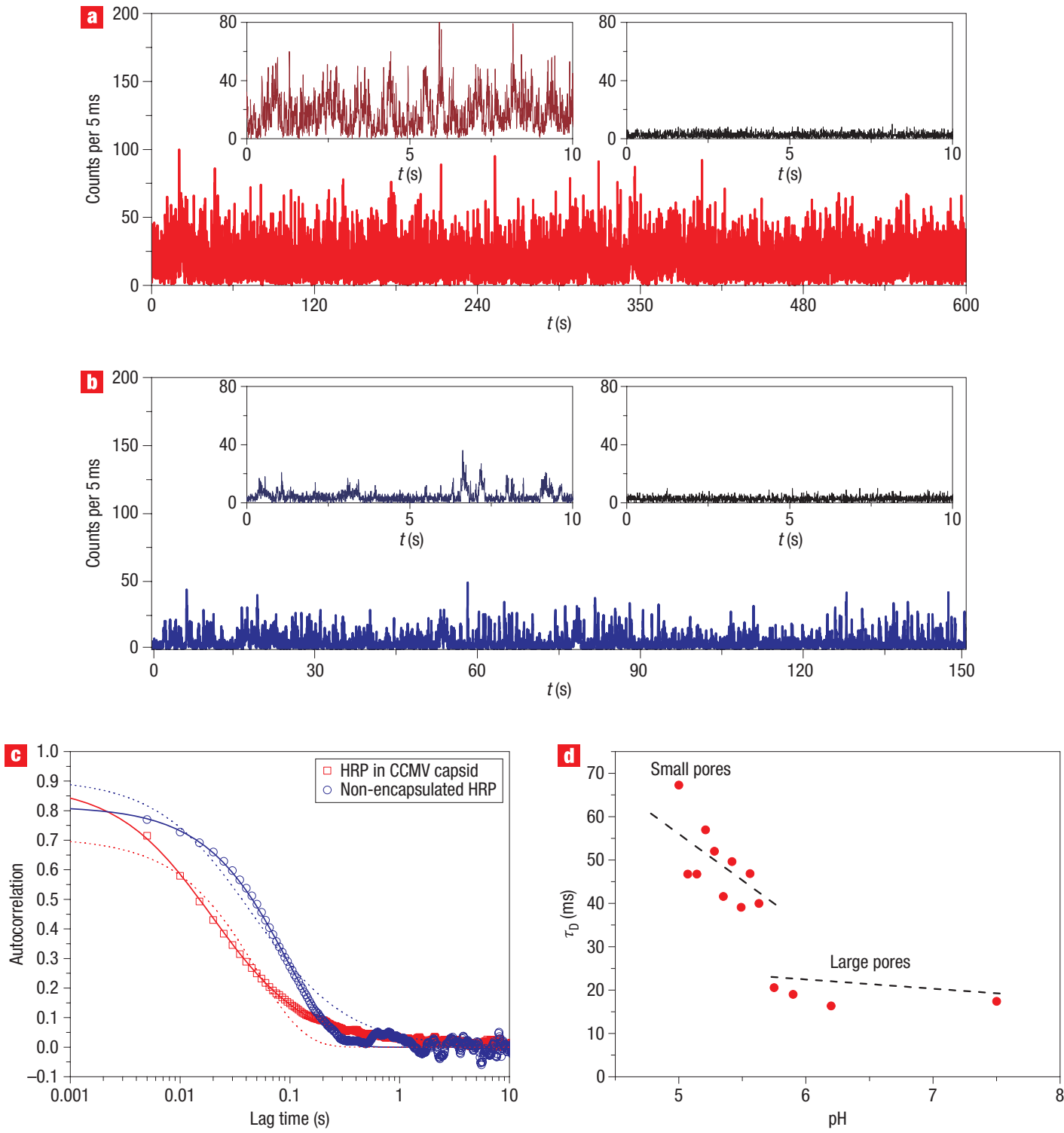

Figure 4 Single-capsid experiments. a,b, Fluorescence intensity time traces measured on bright spots in the confocal fluorescence images obtained from samples in which HRP is either encapsulated inside a capsid (a, as depicted in Fig. 3a) or simply mixed with empty CCMV capsids (b, as depicted in Fig. 3b). Insets in each case: left, 10-s zoom-in; right, background fluorescence measured at dark areas of the images. c. Fluorescence autocorrelation curves of the traces in a and $\mathbf{b}$. Squares: Fluorescence autocorrelation curve of the HRP-CCMV capsid inclusion complex during catalysis. The continuous line is the best fit using a diffusion model. Blue circles: fluorescence autocorrelation curve of the mixture of non-encapsulated HRP and the CCMV capsid. The continuous line is the best fit using a model for a chemical equilibrium ${ }^{31}$. To emphasize the difference between the two models, each curve is also fitted with the model used for the other case (dotted lines), yielding very poor fits. $\mathbf{d}$, Measured product diffusion times $\tau_{\mathrm{D}}$ as a function of $\mathrm{pH}$ during the enzymatic formation of rhodamine $6 \mathrm{G}$ by the HRP-CCMV capsid inclusion complex, showing a step at pH 5.7 indicating a sudden increase in pore size.

virus is compact with small pores $(<2 \mathrm{~nm})$, but at $\mathrm{pH} 7.5$, it is swollen and contains pores of $\geq 2 \mathrm{~nm}$. On standing at this $\mathrm{pH}$, depending on the salt concentration, the virus slowly disassembles into dimers. To investigate the influence of this pore size on the behaviour of the nanoreactor, the apparent diffusion times $\tau_{\mathrm{D}}$ of one single capsid at several $\mathrm{pH}$ values were measured (Fig. 4d; see also Supplementary Information, Fig. S7). The diffusion time $\tau_{\mathrm{D}}$ clearly reveals a step at around $\mathrm{pH}$ 5.7. This experiment indicates that the permeability of the capsid wall increases by a factor $2-3$ as the $\mathrm{pH}$ increases, which is probably associated with the formation of larger pore sizes. These observations, furthermore, indicate that the monitored processes take place inside the capsid cavity.

The simple diffusion model of equation (2) cannot describe the autocorrelation curve for the non-encapsulated HRP enzyme. In this case, the curve is best fitted by

$$
G(t)=A \mathrm{e}^{-t / \tau},
$$

which is a model for a thermodynamic equilibrium ${ }^{31}$ between a fluorescent and a non-fluorescent state, in this case the 
steady-state equilibrium

$$
\text { enzyme } \rightarrow \text { enzyme }- \text { substrate complex } \rightarrow \text { fluorescent enzyme }
$$$$
- \text { product complex }{ }^{*} \rightarrow \text { enzyme. }
$$

In equation(3), $A$ is a pre-exponential constant and $\tau$ is the turnover time. This, together with the observation that the activity is localized, leads us to conclude that the HRP enzyme molecules are adsorbed to the outside of the capsid.

Using the described disassembly/assembly properties of the CCMV, we have shown that enzymes can be loaded in the CCMV capsid. Enzymes encapsulated in a virus particle can be used to study their activity at the single-molecule level. The inclusion is a statistical process in which the number of encased proteins is determined by the starting concentrations of the protein. Under the applied experimental conditions, it can be assumed that, as intended, not more than one HRP enzyme molecule is encapsulated within a CCMV particle. The effects of concentration, protein size and surface charge on the inclusion of enzyme molecules into the capsid are interesting topics for further research.

\section{METHODS}

\section{HRP INCLUSION}

A solution containing the proteins that comprise the CCMV coat $(500 \mu \mathrm{l}$, $\left.15.9 \mathrm{mg} \mathrm{ml}^{-1}\right)$ in sodium acetate buffer $(0.05 \mathrm{M}, \mathrm{pH} 5)$ was dialysed against three changes of Tris- $\mathrm{HCl}$ buffer $(500 \mathrm{ml}, 0.05 \mathrm{M}, \mathrm{pH}$ 7.5) ( $3 \mathrm{~h}$ per change). When the solution reached $\mathrm{pH} 7.5$, the guest enzyme solution $(100 \mu \mathrm{l})$ in Tris- $\mathrm{HCl}$ buffer $(0.05 \mathrm{M}, \mathrm{pH} 7.5)$ was added in excess (66 equivalents of HRP per capsid particleone capsid particle corresponds to 90 capsid protein dimers), and the resulting solution was incubated for $1.5 \mathrm{~h}$. Dialysis of the incubated solution against the initial sodium acetate buffer was carried out under the same dialysis conditions as above. The samples were concentrated and the free guest enzyme was removed using centrifugal filter devices (Centricon YM-100, Millipore).

The samples obtained from the encapsulation and control experiments were analysed and purified by FPLC. Injections of $20-\mu l$ aliquots of the samples on the FPLC column at room temperature were monitored using $\mathrm{UV}$ detection at $280 \mathrm{~nm}$ and the wavelength corresponding to the chromophore present in the guest protein. Fractions of $60 \mu \mathrm{l}$ were collected and the ones corresponding to the purified HRP-containing CCMV capsid were further analysed by fluorescence spectroscopy. The HRP used in the experiments was labelled with Alexa Fluor 532 dye $(\lambda=530 \mathrm{~nm})$. The CCMV capsid containing this guest enzyme displayed significant emission at $\lambda=550 \mathrm{~nm}$ when excited at $\lambda=530 \mathrm{~nm}$ (Fig. 2e), indicating that inclusion of the enzyme had occurred. In the case of the CCMV capsid, no emission at $\lambda=550 \mathrm{~nm}$ was observed.

All buffer solutions used in the experimental work contained $1 \mathrm{mM}$ EDTA, $300 \mathrm{mM} \mathrm{NaCl}, 10 \mathrm{mM} \mathrm{CaCl}$ and $0.2 \mathrm{mM}$ phenylmethylsulphonyl fluoride. Buffers were stored at $4{ }^{\circ} \mathrm{C}$, and the dialysis was performed in a cold room at $4{ }^{\circ} \mathrm{C}$.

\section{MICROSCOPE SET-UP}

Laser light (Spectra-Physics 2080 argon ion laser, $488 \mathrm{~nm}$ ) was coupled into a single-mode optical fibre, passed through a 488 -nm interference filter, reflected by a dichroic beam splitter (Chroma, 505dcxr) and focused on the sample by an oil immersion $\times 100$ objective (Karl Zeiss, NA $=1.30$ ), which was mounted on a Karl Zeiss Axiovert 200 inverted microscope. The confocal volume of the sample beam was determined to be $0.5 \mathrm{fl}$. The power density at the sample was $1-2 \mathrm{~kW} \mathrm{~cm}^{-2}$. Fluorescent light coming from the focal volume was collected by the same objective, passed through the dichroic beamsplitter, filtered (Chroma, HQ500lp), guided through a 50- $\mu \mathrm{m}$ pinhole, and finally focused on an avalanche photo diode (PerkinElmer SPCM-AQR-14), which was coupled to a National Instruments PCI-6036E data acquisition card operating at $20 \mathrm{MHz}$. The sample was mounted onto a JPK TAO nano positioner. Data collection and analyses were carried out with programs written in National Instruments LabVIEW 7.1.

A solution of the CCMV capsid containing HRP $\left(10 \mu \mathrm{l}, 3 \mu \mathrm{g} \mathrm{l} \mathrm{l}^{-1}\right)$ was spincoated at 4,000 r.p.m. on a clean, hydrophilic cover glass and quickly rinsed with
$4 \times 1 \mathrm{ml}$ of MilliQ water. After mounting the sample on the microscope, $200 \mu \mathrm{l}$ of a solution containing $120 \mu \mathrm{M}$ of $\mathrm{H}_{2} \mathrm{O}_{2}$ and $0.5 \mu \mathrm{M}$ of dihydrorhodamine $6 \mathrm{G}$ was added. Dihydrorhodamine $6 \mathrm{G}$ acts as a hydrogen donor in the enzymatic reduction of hydrogen peroxide by HRP, yielding the highly fluorescent product rhodamine $6 \mathrm{G}$.

Received 15 June 2007; accepted 21 August 2007; published 23 September 2007.

References

1. Lu, H. P., Xun, L. \& Xie, S. Single-molecule enzymatic dynamics. Science 282, 1877-1882 (1998).

2. Min, W. et al. Fluctuating enzymes: lessons from single-molecule studies. Acc. Chem. Res. 38, 923-931 (2005)

3. Engelkamp, H. et al. Do enzymes sleep and work? Chem. Commun. 935-940 (2006).

4. Flomenbom, O. et al. Stretched exponential decay and correlations in the catalytic activity of fluctuating single lipase molecules. Proc. Natl Acad. Sci. USA 102, 2368-2372 (2005).

5. Vriezema, D. M. et al. Self-assembled nanoreactors. Chem. Rev. 105, 1445-1489 (2005).

6. Douglas, T. et al. Synthesis and structure of an iron(III) sulfide-ferritin bioinorganic nanocomposite. Science 269, 54-57 (1995).

7. Meldrum, F. C., Heywood, B. R. \& Mann, S. Magnetoferritin—in vitro synthesis of a novel magnetic protein. Science 257, 522-523 (1992).

8. Ueno, T. et al. Size-selective olefin hydrogenation by a Pd nanocluster provided in an apo-ferritin cage. Angew. Chem. Int. Edn 43, 2527-2530 (2004).

9. Seebeck, F. P., Woycechowsky, K. J., Zhuang, W., Rabe, J. P. \& Hilvert, D. A simple tagging system for protein encapsulation. J. Am. Chem. Soc. 128, 4516-4517 (2006).

10. Varpness, Z., Peters, J. W., Young, M. \& Douglas, T. Biomimetic synthesis of an $\mathrm{H}_{2}$ catalyst using a protein cage architecture. Nano Lett. 5, 2306-2309 (2005)

11. Douglas, T. \& Young, M. Host-guest encapsulation of materials by assembled virus protein cages. Nature 393, 152-155 (1998).

12. Douglas, T. et al. Protein engineering of a viral cage for constrained nanomaterials synthesis. $A d v$. Mater. 14, 415-418 (2002).

13. Douglas, T. \& Young, M. Viruses: Making friends with old foes. Science 312, 873-875 (2006).

14. Flynn, C. E., Lee, S.-W., Peelle, B. R. \& Belcher, A. M. Viruses as vehicles for growth, organization and assembly of materials. Acta Mater. 51, 5867-5880 (2003).

15. Shenton, W., Douglas, T., Young, M., Stubbs, G. \& Mann, S. Inorganic-organic nanotube composites from template mineralization of tobacco mosaic virus. Adv. Mater. 11, 253-256 (1999).

16. Dujardin, E., Peet, C., Stubbs, G., Culver, J. N. \& Mann, S. Organization of metallic nanoparticles using tobacco mosaic virus templates. Nano Lett. 3, 413-417 (2003).

17. Mao, C. B. et al. Virus-based toolkit for the directed synthesis of magnetic and semiconducting nanowires. Science 303, 213-217 (2004).

18. Carette, N. et al. A virus-based biocatalyst. Nature Nanotech. 2, 226-229 (2007).

19. Arora, P. S. \& Kirshenbaum, K. Nano-tailoring: Stitching alterations on viral coats. Chem. Biol. 11, $418-420$ (2004).

20. Wang, Q. et al. Bioconjugation by copper(I)-catalyzed azide-alkyne $3+2$ cycloaddition. J. Am. Chem. Soc. 125, 3192-3193 (2003).

21. Hooker, J. M., Kovacs, E. W. \& Francis, M. B. Interior surface modification of bacteriophage MS2 J. Am. Chem. Soc. 126, 3718-3719 (2004).

22. Speir, J. A., Munshi, S., Wang, G. J., Baker, T. S. \& Johnson, J. E. Structures of the native and swollen forms of cowpea chlorotic mottle virus determined by X-ray crystallography and cryoelectron microscopy. Structure 3, 63-78 (1995).

23. Johnson, J. E. \& Speir, J. A. Quasi-equivalent viruses: A paradigm for protein assemblies. J. Mol. Biol. 269, 665-675 (1997)

24. Verduin, B. J. M. Degradation of cowpea chlorotic mottle virus ribonucleic acid in situ. J. Gen. Virol. 39, 131-147 (1978).

25. Verduin, B. J. M. The preparation of CCMV-protein in connection with its association into a spherical-particle. FEBS Lett. 45, 50-54 (1974).

26. Ando, R., Mizuno, H. \& Miyawaki, A. Regulated fast nucleocytoplasmic shuttling observed by reversible protein highlighting. Science 306, 1370-1373 (2004)

27. Habuchi, S. et al. Reversible single-molecule photoswitching in the GFP-like fluorescent protein Dronpa. Proc. Natl Acad. Sci. USA 102, $9511-9516$ (2005).

28. Edman, L., Foldes-Papp, Z., Wennmalm, S. \& Rigler, R. The fluctuating enzyme: a single molecule approach. Chem. Phys. 247, 11-22 (1999).

29. Krichevsky, O. \& Bonnet, G. Fluorescence correlation spectroscopy: the technique and its applications. Rep. Prog. Phys. 65, 251-297 (2002).

30. Kinjo, M. \& Rigler, R. Ultrasensitive hybridization analysis using fluorescence correlation spectroscopy. Nucleic Acids Res. 23, 1795-1799 (1995).

31. Wennmalm, S., Edman, L. \& Rigler, R. Conformational fluctuations in single DNA molecules. Proc Natl Acad. Sci. USA 94, 10641-10646 (1997).

Acknowledgements

This work was supported by the Council for Chemical Sciences of the Netherlands Organization for Scientific Research (NWO-CW) through a TOP grant to R.J.M.N. and Veni \& Vidi Innovative Research Grants to J.J.L.M.C., and by the Royal Netherlands' Academy for Arts and Sciences (R.J.M.N.). The protein Dronpa was a generous gift from J. Hofkens, University of Leuven (Belgium).

Correspondence and requests with respect to the single-molecule spectroscopy studies should be addressed to H.E.; all other requests for materials should be addressed to J.J.L.M.C. Supplementary information accompanies this paper at www.nature.com/naturenanotechnology.

Author contributions

M.C., H.E., J.C. and R.N conceived and designed the experiments; M.C. carried out the capsid isolation and encapsulation experiments and M.C., V.C. and H.E. performed the fluorescence spectroscopy. B.V. contributed to the capsid isolation and encapsulation studies. H.E. analysed the fluorescence data. A.R. P.C., J.M. and R.N. facilitated the fluorescence microscope and N.S. provided the cryo-TEM data.M.C., H.E., J.C and R.N co-wrote the manuscript. All authors discussed the results and commented on the manuscript.

Reprints and permission information is available online at http://npg.nature.com/reprintsandpermissions/ 